\title{
High Pressure Injection Injury of the Hand
}

\author{
Abdul Haque M. Quraishi
}

Received: 10 October 2011 / Accepted: 6 June 2012 /Published online: 21 June 2012

(C) Association of Surgeons of India 2012

\begin{abstract}
High pressure injection injury of the hand looks rather innocuous but has the potential of affecting the function. The radiological picture is quite alarming and it gives a fair idea about the extent of the damage. The description and the images which follow, emphasize the need for an early and aggressive surgical debridement for a good functional outcome.
\end{abstract}

Keywords High pressure injuries · Paint · Injection injuries · Hand

A 25-year-old freelance painter injured himself with a highpressure paint gun, having injected paint in his right palm accidently. He was shown in a different hospital for a swollen hand following trauma, where an incision was made under general anesthesia and a tetanus prophylaxis and injectable antibiotics were given. On the next day when we examined, the hand was swollen, tender, and had a $3 \mathrm{~cm}$ incision on the palmar aspect (Fig. 1). A plain X-ray revealed extensive radiopaque shadow in the right palm (Fig. 2). An aggressive debridement was done under general anesthesia with a tourniquet application. The hand improved with regular dressings over a period of 3 weeks with satisfactory functional outcome.

The severity of high-pressure injection injury depends on the nature, pressure, volume, and toxicity of the injected substance. Increase of pressure within the closed space leads to tamponade, intravascular thrombosis, and spasm of vessels creating circulatory embarrassment. A chemical irritation provokes an acute inflammation. Timing of intervention

A. H. M. Quraishi $(\bowtie)$

Government Medical College,

22, Vijaynagar,

Chhaoni, Nagpur 440013, India

e-mail: am_quraishi@hotmail.com

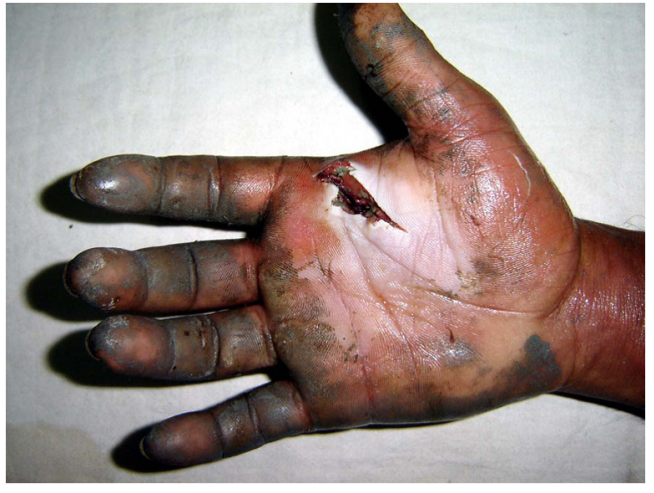

Fig. 1 Swollen right hand of the patient

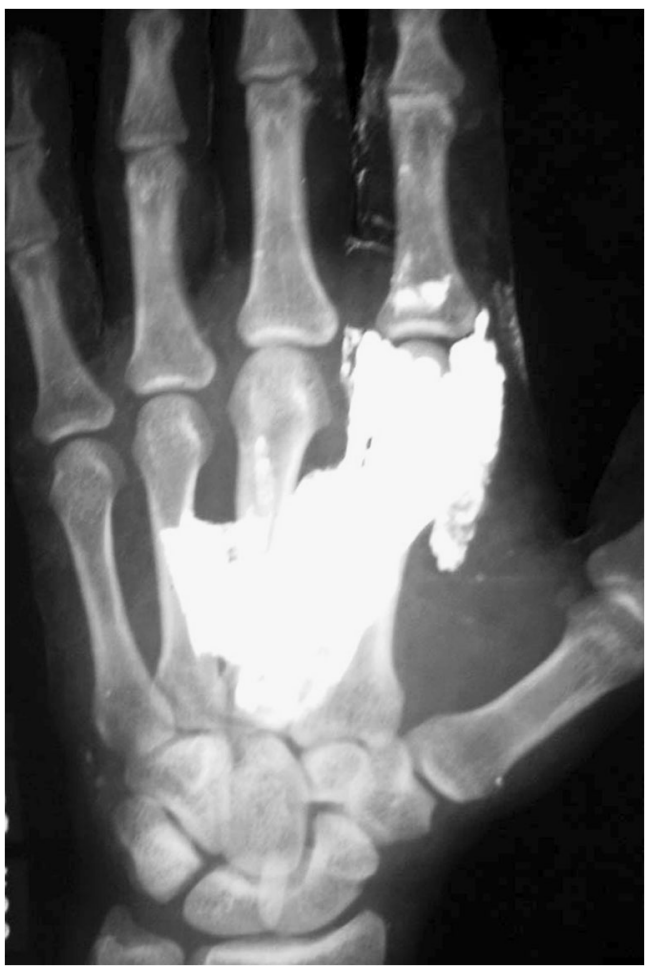

Fig. 2 Radio-opaque paint seen on the x-ray of the right hand 
is an important factor influencing the results. An early, wide decompression and aggressive debridement with complete removal of foreign substances and necrosectomy is recommended in the acute stage and will improve prognosis and outcome. Open wound treatment and second-look operations during the intermediate stage are followed by secondary wound closure with local or free flaps, if necessary [1].
Funding Nil

\section{Reference}

1. Rappold G, Rosenmayr E (2001) High-pressure injection injuries of the hand. Pathogenesis, problems and therapy. Handchir Mikrochir Plast Chir 33(5):332-341 